\title{
Additive Interaction of Work-Related Stress and Sleep Duration on Arthritis Among Middle-Aged Civil Servants
}

\author{
Po-Chang Tseng (D) ${ }^{1,2}$ \\ Ping-Yi Lin ${ }^{3,4}$ \\ Wen-Miin Liang ${ }^{5}$ \\ Wen-Yu Lin (iD) 1,6 \\ Hsien-Wen Kuo (D) ${ }^{1,7}$ \\ 'Institute of Environmental and
} Occupational Health Sciences, National Yang Ming Chiao Tung University, Taipei,

Taiwan; ${ }^{2}$ Health Promotion Administration, Ministry of Health and Welfare, Taipei,

Taiwan; ${ }^{3}$ Department of Nursing,

Hungkuang University, Taichung, Taiwan;

${ }^{4}$ Department of Medical Research, China

Medical University Hospital, Taichung,

Taiwan; ${ }^{5}$ Department of Health Services

Administration, China Medical University,

Taichung, Taiwan; ${ }^{6}$ Environmental

Protection Administration, Executive Yuan,

Taipei, Taiwan; ${ }^{7}$ Institute of Public Health,

National Defense University, Taipei, Taiwan

\begin{abstract}
Aim: Occupational strain is recognized as a risk for arthritis, yet little is known about how psychological stress affects arthritis moderated by sleep duration. The objective of this study is to assess work-related stress using the effort-reward imbalance (ERI) model and the jobdemand-support (JDS) model on arthritis moderated by sleep duration.
\end{abstract}

Methods: A nationwide cross-sectional study randomly collected a total of 11,875 middleaged, employed civil servants from 647 registered governmental institutions. Each participant anonymously and voluntarily filled out a web-based questionnaire and informed consent at the time of the study. Psychosocial work stress was assessed by ERI and JDS measured by a Chinese version of the job content questionnaire.

Results: There were significant odds ratios (ORs) of arthritis positively associated with high ERI $(\mathrm{OR}=1.58)$, high overcommitment $(\mathrm{OC})(\mathrm{OR}=1.57)$, and job demand $(\mathrm{OR}=1.31)$ and negatively associated with job support $(\mathrm{OR}=0.69)$ using multivariate analysis after being adjusted for covariates. For the short sleep duration group, there was an interaction effect of both high ERI and OC on arthritis, with a synergy index of 18.91 and 1.52, respectively. Similarly, there are high ORs of arthritis in both the high job demand and low job support groups. Conclusion: Work-related stress related to arthritis moderated by sleep duration for civil servants. Civil servants with high job demand and low job support should use caution to reduce the risk of arthritis.

Keywords: psychological work stress, effort-reward imbalance, ERI, job-demand-support, JDS, arthritis, sleep duration, civil servants

\section{Introduction}

Arthritis is a global health problem; its two common forms are osteoarthritis (OA) (degenerative joint disease) and rheumatoid arthritis (RA). OA has been reported as associated with certain occupational risk factors such as physical loading and is the leading cause of chronic pain and disability in advanced age. ${ }^{1,2}$ Risk factors of OA contributing to arthritis, include age, sex, obesity, congenital malformations, muscle decline, early injury, metabolic or hormonal disorders, and poor diet. ${ }^{3}$ The risk of OA increases relative to age increasing in groups over the age of 45 but declines after the age of 80 due to the reduction in activity and slow movement. ${ }^{4}$ Generally, women have a greater risk of OA than men, in part because women in and post menopause over the age of 55 may have a lack of hormones that cause OA. ${ }^{5}$ Whereas, occupations that involve physical strain and are typically carried out by men result in higher risk of hip OA than in women. ${ }^{6}$ Trends in obesity and OA among baby boomers in the US suggest that
Correspondence: Hsien-Wen Kuo Institute of Environmental and Occupational Health Sciences, National Yang Ming Chiao Tung University, No. I55, Sec.2, Linong Street, Taipei, II2, Taiwan

Tel +886 2-28272294

Email hwkuo@ym.edu.tw 
obesity has contributed to more cases of arthritis in recent years, even though differences in the prevalence of arthritis are not yet evident. ${ }^{7}$ While obesity was associated with bilateral but not unilateral hip $\mathrm{OA}^{8}{ }^{8}$ growing evidence has indicated job stress is linked to the development of RA, ${ }^{9,10}$ which may be explained by the activation of the stress response system's effect on the associations between the hypothalamicpituitary-adrenal (HPA) axis. ${ }^{11}$

In recent decades, trends in problems associated with psychosocial work stress and risk of diseases in the workplace are worrisome. Since arthritis is a multifactorial disease with strong genetic ${ }^{12,13}$ and occupational components, ${ }^{14,15}$ psychosocial stressors in the etiology and progression of arthritis (including $\mathrm{OA}$ and $\mathrm{RA}$ ) remain indecisive. An article ${ }^{16}$ reviewing 16 articles published between 1987 and 2008 indicated work-related activities as risk factors for $\mathrm{OA}$ and a strong relationship between physical strain experienced while performing physically demanding jobs and the incidents of OA. Heavy physical workloads including kneeling and regular stair climbing, crawling, bending, whole body vibrations, and repetitive movements were the most common occupational risk factors for $\mathrm{OA}$ in several anatomical locations. ${ }^{10}$ The use of the internet was found to have a negative relationship with exercise, physical activity and health. ${ }^{17}$ Additionally, the negative association of insomnia and internet addiction with mental health has been documented and there is high comorbidity between internet addiction and insomnia. ${ }^{18}$

The significant association between sleep duration and osteoarthritis in adults aged more than and equal to 50 years was reported. ${ }^{19}$ Specific occupations with the greatest prevalence rate ratio on $\mathrm{OA}$ of the knee, hip, or hand were female cleaners $(6.2 ; 95 \%$ CI 4.6-8.0), women in the clothing industry $(5.0 ; 95 \%$ CI 3.9-6.3), male masons and other construction workers $(2.9 ; 95 \%$ CI 2.6-3.3), and agriculture male and female workers $\left(2.8 ; 95 \%\right.$ CI 2.5-3.2). ${ }^{14}$ Generally, the risk of OA increased with cumulative years in the occupation of farming, construction, or healthcare work in both men and women. ${ }^{20}$ In addition, high psychological demands, low decision latitude, or the combination of job strain, may be recognized as risk factors in the pathogenesis of several diseases (eg cardiovascular disease (CVDs), metabolic diseases (MDs), and autoimmune rheumatic diseases, including RA). For the sake of prevention of arthritis, precautions must be taken, and there is a need to address the various factors of job characteristics leading to the risk of arthritis, such as physical strain and psychological stress. Very few studies have described the prevalence of arthritis for civil servants and assess the association with psychological stress. $^{21}$

Despite the growing evidence showing increases in the prevalence of arthritis, the association with psychological stress in the workplace remain unconvincing and vexing. In addition, long-term exposure to psychological stress directly affects sleep quality, which may worsen RA or OA pain and symptoms. Yet little is known about how psychological stress and job support interact with arthritis when moderated by sleep duration. Therefore, our study assesses psychological stress using effort-reward imbalance (ERI) model and job-demand-support (JDS) model on arthritis moderated by sleep duration for public servants.

\section{Methods}

\section{Study Population}

Our proposal was approved by the institutional review board (IRB) from China Medical University (CMUH105-REC3 -091) and the study was conducted in accordance with the Declaration of Helsinki. A nationwide cross-sectional study randomly collected a total of 11,875 middle aged (40-60 years old) civil servants from 647 registered governmental institutions using multistage stratified cluster sampling.

All participants filled out an informed consent form online before participating in this study. Each participant anonymously and voluntarily completed a web-based questionnaire at the study time, with an overall response rate of $35.8 \%$. Reasons for participant non-response included personal vacations, requested time off, or having limited time to fill out the questionnaire, they do not affect the objective of the study.

\section{Main Variables}

The web questionnaire was used to collect demographic data (eg, age, gender, educational level, and marital status), work context (eg, work duration, managerial position, and level of government employment), lifestyle habits (eg, smoking, alcohol consumption, betel nut chewing, sleep duration, and physical inactivity), psychological variables (effort-reward imbalance (ERI), over-commitment (OC), job demand (JD), and job support (JS)), and history of diseases. Physical inactivity was defined as less than 30 minutes of activity 3 days a week. Short sleep duration was defined as less than 6 hours of sleep a night during workdays. Based on Taiwan's guideline for adult men and women from the Health Promotion Administration (HPA), obesity was defined using body mass index $(\mathrm{BMI})>27$, which was calculated by dividing weight by 
height $\left(\mathrm{kg} / \mathrm{m}^{2}\right) .{ }^{22}$ Participants with perceived work-related stress were assessed by the ERI model and the job-demandsupport model (JDS). ERI at work was calculated by using a modified short-version questionnaire, ${ }^{23}$ which contained 3 items that measured effort and 10 items that measured reward. The ERI ratio for each study participant was computed using the sum scores for effort as the numerator (Effort) and the sum scores for reward as the denominator (Reward) multiplied by a correction factor of 0.43 [(Effort/3)/(Reward/7)]. An ERI ratio $>1$ indicates an exposure to high ERI at work, which also constitutes a perceived psychosocial work stress. Six items from a Taiwanese-version of the questionnaire were used to measure OC. ${ }^{24}$ Cronbach's alpha coefficients for each scale in the ERI model ranged from $0.65-0.88$, which is consistent with Siegrist's study ${ }^{23}$ of $0.61-0.91$. The JD scale included eight items that were measured with the Likert's scale: strongly agree (4 points), agree ( 3 points), disagree ( 2 points) and strongly disagree (1 point). The maximum score was 32 , and a higher score represented a higher job demand level. JS was measured by eight items, which included four items for work support and guidance from colleagues and four items for support and guidance from supervisors. The Likert's scale was used to measure JD and JS: strongly agree (4 points), agree (3 points), disagree ( 2 points), and strongly disagree (1 point). Cronbach's alpha coefficients were all above 0.80 for JD and JS. ${ }^{25}$ Scales of OC, JD, and JS were classified into two groups: the upper quartile $(>75 \%)$ of scores for the high group and $<75 \%$ for the low group.

\section{Outcome Measurement}

Each participant was assessed by three questions in a webquestionnaire, including "Have you frequently experienced joint pain over the past year?", "Do you suffer from arthritis diagnosed by a physician?", and "Are you treated or monitored by a hospital?". In the study, we defined arthritis by physician diagnoses. Arthritic symptoms, which joint or joints affected, commonly included pain when walking and stiffness after resting caused by degenerative arthritis (osteoarthritis). An annual health examination in Taiwan is accessible to diagnose arthritis by radiographic criteria for each public servant. In order to respect participant privacy, we did not obtain detailed information on classification, treatment, and predisposing factors for arthritis. Participants with arthritis in the study may include two common types of osteoarthritis (degenerative joint disease) and rheumatoid arthritis.

\section{Statistical Analysis}

All data was analyzed using SPSS software (version 24.0, Chicago, IL, USA). Chi-square test was used to examine the differences between demographic data in the arthritic and non-arthritic groups. Univariate analysis was used to assess the correlation between risk factor and arthritis. Odds ratio (OR) and a 95\% confidence interval (CI) were used to assess the interaction effects of ERI and OC on arthritis for the long sleep duration and short sleep duration groups using multiple logistic analysis after adjusting for covariates. Similarly, effects of job demand and job support on arthritis for the long sleep duration and short sleep duration groups were analyzed using multivariate analysis after adjusting for covariates. The $P$-values $<0.05$ were considered to be statistically significant. The additive interaction was measured using relative excess risk due to interaction (RERI), attributable proportion due to interaction (AP), and synergy index (S). A significant interaction effect was indicated by CIs of RERI $>0, A P>0$, or $\mathrm{S}>1$. An Excel sheet was used to quickly calculate additive interaction. ${ }^{26}$

\section{Results}

Table 1 indicates demographic information in physician diagnosed arthritis. There was a significant high prevalence in senior persons $(6.5 \%)$, work duration $>20$ years $(4.6 \%)$, education with senior high school levels (5.7\%), and management (5.1\%). Gender, marital status, and level of government employment were not significant differences in the two groups. Univariate analysis of risk factors on physiciandiagnosed arthritis is shown in Table 2. Significantly high ORs on arthritis were correlated with short sleep duration $(\mathrm{OR}=1.36)$, persons with $\mathrm{DM}(\mathrm{OR}=2.46)$, gout $(\mathrm{OR}=$ 3.07), high ERI ( $\mathrm{OR}=1.55)$, high $\mathrm{OC}(\mathrm{OR}=1.61)$, high job demand $(\mathrm{OR}=1.31)$ and high job support $(\mathrm{OR}=0.70)$. There were no significant differences for smoking, alcohol consumption, betel nut chewing, physical inactivity, exposure to ETS, and obesity in relation to arthritis.

Table 3 shows job characteristics including ERI, OC, job demand, and job support correlated with physiciandiagnosed arthritis after adjusting for work duration, gender, educational level, marital status, managerial position, short sleep duration, smoking, and obesity. There were significant correlations between job characteristics and arthritis. Using multivariate analysis after adjusting for covariates, odds ratios (ORs) of arthritis positively correlated with high ERI $(\mathrm{OR}=1.58)$, high $\mathrm{OC}(\mathrm{OR}=1.57)$, and high job demand $(\mathrm{OR}$ 
Table I Demographic Information in Physician Diagnosed Arthritis $(\mathrm{N}=\mathrm{II}, 875)$

\begin{tabular}{|c|c|c|c|}
\hline & No Arthritis & Arthritis & $p$ \\
\hline Gender & & & 0.446 \\
\hline Men & 5239 (95.7\%) & $236(4.3 \%)$ & \\
\hline Women & 6097 (95.4\%) & $294(4.6 \%)$ & \\
\hline Age (years) & & & $<0.001$ \\
\hline $40-50$ & 7429 (96.6\%) & 259 (3.4\%) & \\
\hline $5 I-60$ & $3916(93.5 \%)$ & $27 \mid(6.5 \%)$ & \\
\hline Education level & & & 0.027 \\
\hline Senior high school & $763(94.3 \%)$ & $46(5.7 \%)$ & \\
\hline College & 2699 (95.2\%) & 137 (4.8\%) & \\
\hline Undergraduate & 4955 (95.5\%) & $235(4.5 \%)$ & \\
\hline Graduate & 2897 (96.4\%) & $108(3.6 \%)$ & \\
\hline Marital status & & & 0.557 \\
\hline Unmarried & $1710(95.4 \%)$ & $82(4.6 \%)$ & \\
\hline Married & $9458(95.6 \%)$ & $437(4.4 \%)$ & \\
\hline Other & I7I (94.0\%) & II (6.0\%) & \\
\hline Work duration (years) & & & $<0.001$ \\
\hline$<3$ & $320(97.6 \%)$ & $8(2.8 \%)$ & \\
\hline $3-10$ & II 39 (97.3\%) & $32(2.7 \%)$ & \\
\hline $10-20$ & 8504 (95.5\%) & $40 \mathrm{I}(4.5 \%)$ & \\
\hline$>20$ & 1376 (93.9\%) & 89 (4.6\%) & \\
\hline Managerial position & & & 0.039 \\
\hline Yes & 3307 (94.9\%) & 177 (5.1\%) & \\
\hline No & $804 \mid(95.8 \%)$ & $353(4.2 \%)$ & \\
\hline Level of government employment & & & 0.052 \\
\hline Central & $5176(95.9 \%)$ & $219(4.1 \%)$ & \\
\hline Local & 6168 (95.2\%) & $3 I I(4.8 \%)$ & \\
\hline
\end{tabular}

Table 2 Univariate Analysis of Risk Factors on Physician Diagnosed Arthritis

\begin{tabular}{|c|c|c|c|}
\hline & $\begin{array}{c}\text { Total } \\
(\mathbf{N}=\mid \text { I , 875) }\end{array}$ & $\begin{array}{l}\text { Arthritis } \\
(N=530)\end{array}$ & OR $(95 \% \mathrm{Cl})$ \\
\hline Smoking & 1986 (17.6\%) & 104 (19.6\%) & $1.14(0.92-1.42)$ \\
\hline Alcohol drinking & I57| (I3.9\%) & 63 (11.9\%) & $0.84(0.64-1.09)$ \\
\hline Betel nut chewing & 639 (5.7\%) & $25(4.7 \%)$ & $0.83(0.55-1.25)$ \\
\hline Physical inactivity & 8329 (73.6\%) & 397 (74.9\%) & $\mathrm{I} .07(0.88-1.3 \mathrm{I})$ \\
\hline Short sleep duration & 4998 (44.1\%) & $274(51.7 \%)$ & $1.36 * *(1.14-1.62)$ \\
\hline ETS exposure & $24 I 5(21.4 \%)$ & 118 (22.3\%) & $1.05(0.86-1.30)$ \\
\hline Obesity & I780 (I5.8\%) & $93(17.5 \%)$ & $1.13(0.90-1.43)$ \\
\hline DM & 374 (3.3\%) & $4 \mathrm{l}(9.9 \%)$ & $2.46 * *(1.76-3.44)$ \\
\hline Gout & $302(2.7 \%)$ & $4 \mathrm{I}(7.7 \%)$ & $3.07 * *(2.19-4.30)$ \\
\hline High ERI & $5308(47.2 \%)$ & 307 (58.0\%) & $1.55^{* *}(1.30-1.85)$ \\
\hline High OC & 4528 (40.1\%) & 275 (5I.9\%) & $1.6 I^{* *}(1.35-1.92)$ \\
\hline Job demand & $2392(21.2 \%)$ & $138(26.0 \%)$ & I.3I** (I.07-I.60) \\
\hline Job support & $6598(58.4 \%)$ & 262 (49.4\%) & $0.70 * *(0.58-0.83)$ \\
\hline
\end{tabular}

Note: $* * 00.001$.

$=1.31$ ). However, there are negative correlations between high job support $(\mathrm{OR}=0.69)$ and arthritis.

Exposure to ERI and OC on odds ratios (ORs) of arthritis in the long sleep duration group and short sleep duration group using multiple logistic regression adjusted for age, gender, education level, income, marital status, managerial position, level of employing government, obesity, and smoking is shown in Table 4. There are consistently higher ORs 
Table 3 ERI, OC, Job Demand and Job Support Correlated with Physician-Diagnosed Arthritis After Adjusting for Work Duration, Gender, Educational Level, Marital Status, Managerial Position, Short Sleep Duration, Smoking and Obesity

\begin{tabular}{|c|c|}
\hline & aOR $(95 \% \mathrm{Cl})$ \\
\hline \multicolumn{2}{|l|}{ ERI } \\
\hline Low & I \\
\hline High & $1.58 * *(1.31-1.89)$ \\
\hline \multicolumn{2}{|l|}{$O C$} \\
\hline Low & 1 \\
\hline High & $1.57 * *(1.32-1.87)$ \\
\hline \multicolumn{2}{|l|}{ Job demand } \\
\hline No & 1 \\
\hline Yes & $1.31 * *(1.07-1.60)$ \\
\hline \multicolumn{2}{|l|}{ Job support } \\
\hline No & 1 \\
\hline Yes & $0.69 * *(0.58-0.83)$ \\
\hline
\end{tabular}

Note: ${ }^{* *} p<0.001$.

of exposure to high ERI and high OC on arthritis in the short sleep duration group than those in the long sleep duration group. Both high ERI and high OC groups had significantly high ORs of 1.73 in the long sleep duration group and 2.41 in the short sleep duration group, with synergy index of 18.91 and 1.52, respectively. In sum, the effects of ERI and $\mathrm{OC}$ on arthritis is moderated by sleep duration.

Table 5 shows exposure to job demand and job support on odds ratio (OR) of arthritis in the long sleep duration and short sleep duration groups using multiple logistic regression after adjusting for age, gender, education levels, income, marital status, managerial position, level of employing government, obesity, and smoking. There are significantly high ORs in high job demand and low job support $(\mathrm{OR}=2.07)$ and in low job demand and low job support $(\mathrm{OR}=1.44)$ in the short sleep duration group, with a synergy index of 1.27. In the long sleep duration group, high job demand and low job support had an OR of 1.48, and low job demand and low job support significantly had an OR of 1.58 with a synergy index of 0.48 . In total, high job demand with low job support significantly had an OR of 1.98, low job demand and low job support significantly had an OR of 1.53. The effects of job demand and job support on arthritis differed in the two sleep duration groups. Therefore, the effects of job demand and job support on arthritis is moderated by sleep duration.

\section{Discussion}

Arthritis, with more than 100 different types, is not a single disease and is not well understood. A multilevel analysis on an individual level in age, sex, low income status, low education level, aboriginal origin, current smoking status, and overweight status/obesity described a significant association with reports of arthritis. At the regional level, low-income regions were associated with a greater likelihood of reported arthritis after adjusting for individual socioeconomic status (SES). ${ }^{27}$ In the current study, there was a significant high prevalence of arthritis in senior persons $(6.5 \%)$ and work duration more than 20 years $(4.6 \%)$ but there were no significant differences between the two groups regarding gender, marital status, and level of government employment.

Age and hip trauma were significantly associated with hip OA among men but was not found in women. ${ }^{8}$ However, the Framingham Osteoarthritis Study found that men $(24.7 \%)$ had a significantly higher prevalence of radiographic hip OA compared to women (13.6\%), but men did not have a higher prevalence of symptomatic hip OA compared to women $(5.2 \%$ vs $3 \%, \mathrm{p}=0.08) .{ }^{28}$

Table 4 Interaction Effects of Exposure to ERI and OC on Odds Ratios (ORs) of Arthritis in the Long Sleep Duration and Short Sleep Duration Using Multiple Logistic Regressions Adjusted for Age, Gender, Education Levels, Income, Marital Status, Managerial Position, Level of Employing Government, Obesity, and Smoking

\begin{tabular}{|c|c|c|c|c|}
\hline & & Long Sleep Duration & Short Sleep Duration & Total \\
\hline ERI & OC & OR $(95 \% \mathrm{Cl})$ & OR $(95 \% \mathrm{Cl})$ & OR $(95 \% \mathrm{Cl})$ \\
\hline$\leqq 1$ & Low & 1 & 1 & 1 \\
\hline$>1$ & Low & $1.03(0.72-1.48)$ & $1.5 \mathrm{I} *(1.03-2.2 \mathrm{I})$ & $1.23(0.92-1.65)$ \\
\hline$\leqq 1$ & High & $1.01(0.68-1.50)$ & $1.42(0.92-2.20)$ & $1.30 *(1.00-1.68)$ \\
\hline$>1$ & High & $1.73 * *(1.27-2.35)$ & $2.41 * *(1.73-2.34)$ & $2.19 * *(1.76-2.73)$ \\
\hline RERI & & $0.69(-0.03-|.4|)$ & $0.48(-0.55-1.50)$ & $0.67(-0.24-1.58)$ \\
\hline AP & & $0.40(-0.02-0.82)$ & $0.20(-0.22-0.62)$ & $0.31(-0.10-0.71)$ \\
\hline Synergy index & & I8.9| (NA) & $1.52(0.50-4.60)$ & $2.28(0.36-14.44)$ \\
\hline
\end{tabular}

Notes: ${ }^{*}<0.01 .{ }^{* *} p<0.001$. 
Table 5 Interaction of Exposure to Job Demand and Job Support on Odds Ratio (OR) of Arthritis in the Long Sleep Duration and Short Sleep Duration Groups Using Multiple Logistic Regressions After Adjusting for Age, Gender, Education Levels, Income, Marital Status, Managerial Position, Level of Employing Government, Obesity, and Smoking

\begin{tabular}{|c|c|c|c|c|}
\hline & & Long Sleep Duration & Short Sleep Duration & Total \\
\hline Job demand & Job support & OR $(95 \% \mathrm{Cl})$ & OR $(95 \% \mathrm{Cl})$ & OR $(95 \% \mathrm{Cl})$ \\
\hline Low & High & 1 & 1 & 1 \\
\hline High & High & $1.42(0.96-2.11)$ & 1.41 (0.96-2.09) & $1.49 * *(1.13-1.97)$ \\
\hline Low & Low & $1.58 * *(1.19-2.10)$ & $1.44 *(1.07-1.93)$ & $1.53^{* *}(1.25-1.88)$ \\
\hline High & Low & $1.48(0.91-2.43)$ & $2.07 * *(1.42-3.04)$ & $1.98 * *(1.47-2.67)$ \\
\hline RERI & & $-0.52(-1.6 I-0.57)$ & $0.23(-0.76-1.21)$ & $-0.05(-1.09-1.00)$ \\
\hline AP & & $-0.35(-1.06-0.35)$ & $0.11(-0.37-0.58)$ & $-0.02(-0.55-0.50)$ \\
\hline Synergy index & & $0.48(0.15-1.56)$ & $1.27(0.39-4.10)$ & $0.95(0.36-2.63)$ \\
\hline
\end{tabular}

Notes: ${ }^{*} p<0.01 .{ }^{* *} p<0.001$.

Prevalence of knee OA was $15 \%$, and women were about double of that among men, of an estimated 3.5 million patients in Taiwan. In the present study, only $4.5 \%$ of middleaged public servants had physician-diagnosis arthritis, which may be underestimated due to ongoing hospitalization, early retirement, and job turnover. It is similar to previous studies in that there is a higher prevalence in seniors, long work durations, low educational levels, and high psychological stress, but no significant differences occur in men (4.3\%) and women (4.6\%). Severity of OA increases gradually with age and repetitive activity of joints over a long time period resulting in a loss of strength and function. ${ }^{29} \mathrm{~A}$ US based population study for older adults indicated a $5 \mathrm{~kg} / \mathrm{m}^{2}$ increase in BMI increased the risk of developing knee OA by $32 \%^{30}$ and by $35 \%$ in meta-analysis of prospective studies. ${ }^{31}$ In a Korean nationwide survey, blue collar, agribusiness, and low-level positions were at a higher risk for knee OA and knee pain. The prevalence of radiological knee OA was 25\% in men aged 50 years and over, ${ }^{32}$ which was lower than the $31.2 \%$ from Dillon's US study ${ }^{33}$ of men aged above 60 years.

The mechanism of OA involves multifactorial etiologies affecting the function of the joints, including overweight, occupational injuries, and trauma induced motor patterns. The primary source of joint pain during movements are articular cartilage injuries that create friction on the contact surface of joints resulting in inflammatory reactions that limit activity. Workers carrying loads, truck drivers, obese persons can also create a heavy load on joints. Heavy physical workload is not a common job characteristic for public servants, but high psychosocial stress frequently occurs due to various challenges from unexpected economic downturns and changes in Taiwan's government administration. Job strain and burnout lead to an increase in disturbed sleep and irregular diet behaviors, as well as, an increased risk of psychiatric syndromes and major depression. ${ }^{34-36}$ Public servants with high job strain in Taiwan can be attributed to bureaucratic job characteristics, such as irrational demands or pressure from managers, resulting in a high risk of arthritis. Our results show there were significant correlations between psychosocial works stress and arthritis using multivariate analysis after adjusting for covariates. Prevalence of arthritis was positively correlated with high ERI, high OC, and high job demand, but negatively correlated with high job support. Our results highlight that the effect of psychosocial stress on arthritis were significant in the short sleep duration group. Most patients with arthritis do not have good sleep quality. Therefore, sleep disturbances are common in arthritis patients and contribute to poor work performance and loss of quality of life. Based on a systematic review of risk for hip $\mathrm{OA},{ }^{6}$ the lifting of heavy loads increases the high risk of hip OA in men $(\mathrm{RR}=2.09)$ and in women $(\mathrm{RR}=1.41)$. Physically demanding work with heavy loads, heavy manual work, or prolonged walking and standing also increases the risk of hip OA by approximately $150 \%$ in men $(\mathrm{RR}=2.46)$ and $40 \%$ in women $(\mathrm{RR}=1.38)$.

To date, little is known about the effects of exposure to ERI and job demand on arthritis. Our findings are consistent with other evidence that suggests that psychosocial stress is associated with arthritis and the effect is worse in the short sleep duration group. A Swedish EIRA study ${ }^{37}$ indicated a lower risk of RA associated with high psychological job demands $(\mathrm{OR}=0.8)$, but higher correlated with low decision latitude $(\mathrm{OR}=1.6)$, which is explained by the long-lasting stress that may result in the release of 
neurotransmitters and hormones and immune cells, leading to pro-inflammatory effects and the risk of developing RA. ${ }^{38}$ In the early 1990 s, a hypothesis was proposed that susceptibility to autoimmune disease was linked to a hypoactive hypothalamo-pituitary-adrenal (HPA) axis. However, Harbuz et $\mathrm{al}^{39}$ suggest that the original hypothesis is in need of modification to develop the regulation of the HPA in disease in preclinical models and with RA patients, altering negative feedback regulation of the HPA axis. The HPA axis, which has been recognized as the body's "stress system", and which ultimately controls levels of cortisol and other stress-related hormones, is generally underactive in people suffering from burnout. ${ }^{40}$ Our results may propose civil servants suffered from perceived work-related stress and burnout, which means the HPA axis tends to be underactive. Therefore, public servants with long-term stress had serious physical and mental symptoms which can result in negative feedback to the HPA axis, resulting in a high risk of arthritis. However, consequences of the subtle HPA alterations in RA for the disease development remain unclear.

\section{Limitation and Strength}

Our study has several limitations. First, our study used a cross-sectional design, so it is hard to establish causality between perceived work-related stress and the development of arthritis. Second, because ERI and job demand can have time-lagged effects on the progression of diseases, a longitudinal study is needed to examine the causal patterns of ERI and job demand on arthritis. All data measures were based on self-reports using a web questionnaire, so we could not directly validate our data due to occupational privacy. Nevertheless, our study evaluated the consistency between using a web questionnaire and in-person interview, between high and low response rate institutions. No significant differences were found in our findings. Third, because our study was an observational study, various confounding factors could not be well controlled, such as genetic factors and work-family conflict etc. Using multivariate analysis adjusted for age, gender, smoking and obesity, our results indicate the effects of ERI and job demand on arthritis and moderated by sleep duration. Finally, our results may have a "healthy worker effect", which can be attributed to early retirement or layoffs, and may result in an underestimation of the relationship between perceived work-related stress and prevalence of arthritis. The precise mechanisms need further research, specifically longitudinal research in which job strain or burnout can be more directly assessed and temporal changes over time that mediate arthritis can be measured. However, this study also has several strengths. To our knowledge, this is the first nation-wide study to examine the association between perceived work-related stress and arthritis in the workplace for public servants. Our results not only found joint effects of both exposure to ERI and OC on arthritis but also found negative effects in job support. In addition, our findings not only suggest that psychosocial stress associated with arthritis, but also indicated the effect is worse in the short sleep duration group. Public servants with high psychosocial stress correlated with chronic diseases may be modified through personal healthy lifestyles, such as balanced diet intake, regular physical activity and sufficient sleep duration. In the work environment with a high work pace, competitiveness, and efficiency, it is possible that lack of stress reduction is an even more important health problem for public servants than is the frequency of muscular activation. It is crucial that the workers with arthritis were associated with substantial workplace activity limitations and then to accommodate their health and work needs through flexible schedules, supplemental equipment, modified job duties, and work-at-home arrangements. More importantly, an intervention program for reduction of work-related stress should be promptly initiated for organizations with high psychosocial stress and consequently used for follow-up evaluations on the effectiveness of the program.

\section{Conclusion}

Public servants with high ERI, high OC and job demand had higher ORs of arthritis, but these are negatively associated with job support. For the short sleep duration group, both high ERI and OC groups had significantly high ORs of arthritis, with a synergy index of 18.91 and 1.52, respectively. Similarly, there are high ORs of arthritis in both the high job demand and low job support groups. Facing challenges from bureaucratic job characteristics, this highlights potential vulnerabilities of public servants with psychosocial work stress that need to be eliminated and updated by an employee assistance program to help reduce the risk of arthritis.

\section{Ethics approval and consent to participate}

The study had ethical approval from the China Medical University (CMUH105-REC3-091). Participants were also informed that the data would be handled confidentially. Information about the study was given to all participants 
and participation was based on written and oral informed consent.

\section{Acknowledgements}

The authors gratefully acknowledge the staff of Taiwan's Health Promotion Administration for providing administrative and budget support. The authors would also like to thank all participants for completing the questionnaires.

\section{Funding}

This study was supported by funding from TobaccoHealth and Welfare Surcharge, Health Promotion Administration, Ministry of Health and Welfare, Executive Yuan, Taiwan, ROC (Civil servants health survey program 2016/ B1050406), China Medical University (CMU-110-S-17 and CMU-110-S-24), and Ministry ofScience and Technology, Taiwan (MOST 109-2410-H-039-002, MOST 110-2314-B-A49A-526 and MOST 110-2410-H039-002).

\section{Disclosure}

The content of this research may not represent the opinion of the Health Promotion Administration, Ministry of Health and Welfare. The authors report no conflicts of interest in this work.

\section{References}

1. Seok H, Choi SJ, Yoon JH, et al. The association between osteoarthritis and occupational clusters in the Korean population: a nationwide study. PLoS One. 2017;12(1):e0170229. doi:10.1371/ journal.pone.0170229

2. Abramoff B, Caldera FE. Osteoarthritis: pathology, diagnosis, and treatment options. Med Clin North Am. 2020;104(2):293-311. doi:10.1016/j.mcna.2019.10.007

3. Sowers M. Epidemiology of risk factors for osteoarthritis: systemic factors. Curr Opin Rheumatol. 2001;13(5):447-451. doi:10.1097/ 00002281-200109000-00018

4. Shane Anderson A, Loeser RF. Why is osteoarthritis an age-related disease? Best Pract Res Clin Rheumatol. 2010;24(1):15-26. doi:10.1016/j.berh.2009.08.006

5. Stevens-Lapsley JE, Kohrt WM. Osteoarthritis in women: effects of estrogen, obesity and physical activity. Women's Health. 2010;6 (4):601-615. doi:10.2217/whe.10.38

6. Bergmann A, Bolm-Audorff U, Krone D, et al. Occupational strain as a risk for hip osteoarthritis. Dtsch Arztebl Int. 2017;114(3536):581-588. doi:10.3238/arztebl.2017.0581

7. Leveille SG, Wee CC, Iezzoni LI. Trends in obesity and arthritis among baby boomers and their predecessors, 1971-2002. Am J Public Health. 2005;95(9):1607-1613. doi:10.2105/ AJPH.2004.060418

8. Tepper S, Hochberg MC. Factors associated with hip osteoarthritis: data from the First National Health and Nutrition Examination Survey (NHANES-I). Am J Epidemiol. 1993;137:1081-1088. doi:10.1093/oxfordjournals.aje.a116611
9. Lee YC, Agnew-Blais J, Malspeis S, et al. Post-traumatic stress disorder and risk for incident rheumatoid arthritis. Arthritis Care Res (Hoboken). 2016;68(3):292-298. doi:10.1002/acr.22683

10. Yucesoy B, Charles LE, Baker B, Burchfiel CM. Occupational and genetic risk factors for osteoarthritis: a review. Work. 2015;50 (2):261-273. doi:10.3233/WOR-131739

11. Cutolo M. The role of the hypothalamus-pituitary-adrenocortical and -gonadal axis in rheumatoid arthritis. Clin Exp Rheumatol. 1998;16 (1):3-6.

12. Spector TD, MacGregor AJ. Risk factors for osteoarthritis: genetics. Osteoarthritis Cartilage. 2004;12(SupplA):S39-44. doi:10.1016/j. joca.2003.09.005

13. Glyn-Jones S, Palmer AJ, Agricola R, et al. Osteoarthritis. Lancet. 2015;386(9991):376-387. doi:10.1016/S0140-6736(14)60802-3

14. Rossignol M, Leclerc A, Allaert FA, et al. Primary osteoarthritis of hip, knee, and hand in relation to occupational exposure. Occup Environ Med. 2005;62(11):772-777. doi:10.1136/oem.2005.020057

15. Nakata K, Tsuji T, Vietri J, Jaffe DH. Work impairment, osteoarthritis, and health-related quality of life among employees in Japan. Health Qual Life Outcomes. 2018;16(1):64. doi:10.1186/s12955018-0896-9

16. Aluoch MA, Wao HO. Risk factors for occupational osteoarthritis: a literature review. $A A O H N$ J. 2009;57(7):283-290. doi:10.1177/ 216507990905700706

17. George LX, Elisavet PD. The relation between physical activity and the use of internet in school children aged 13-15 years old. Swedish J Sci Res. 2016;3:1-7.

18. Cheung LM, Wong WS. The effects of insomnia and internet addiction on depression in Hong Kong Chinese adolescents: an exploratory cross-sectional analysis. $J$ Sleep Res. 2011;20(2):311-317. doi:10.1111/j.1365-2869.2010.00883.x

19. Cho Y, Jung B, Lee YJ, et al. Association between sleep duration and osteoarthritis and their prevalence in Koreans: a cross-sectional study. PLoS One. 2020;15(4):e0230481. doi:10.1371/journal.pone.0230481

20. Andersen S, Thygesen LC, Davidsen M, Helweg-Larsen K. Cumulative years in occupation and the risk of hip or knee osteoarthritis in men and women: a register-based follow-up study. Occup Environ Med. 2012;69(5):325-330. doi:10.1136/oemed-2011-100033

21. Mutambudzi M, Henkens K. Chronic health conditions and work-related stress in older adults participating in the Dutch workforce. Eur J Ageing. 2020;17(4):499-508. doi:10.1007/s10433020-00554-x

22. Chu NF. Prevalence of obesity in Taiwan. Obes Rev. 2005;6 (4):271-274. doi:10.1111/j.1467-789X.2005.00175.x

23. Siegrist J. Adverse health effects of high effort - low reward conditions at work. J Occup Health Psychol. 1996;1:27-43. doi:10.1037/ 1076-8998.1.1.27

24. Tseng HP, Cheng YW. Reliability and validity of the Chinese demand- control- support model and effort-reward imbalance model questionnaires: a study among employees of the microelectronic industry. Taiwan J Public Health. 2002;21:420-432.

25. Cheng Y, Luh WM, Guo YL. Reliability and validity of the Chinese Version of the Job Content Questionnaire (C-JCQ) in Taiwanese workers. Int $J$ Behav Med. 2003;10(1):15-30. doi:10.1207/ S15327558IJBM1001_02

26. Andersson T, Alfredsson L, Källberg H, Zdravkovic S, Ahlbom A. Calculating measures of biological interaction. Eur J Epidemiol. 2005;20(7):575-579.

27. Canizares M, Power JD, Perruccio AV, Badley EM. Association of regional racial/cultural context and socioeconomic status with arthritis in the population: a multilevel analysis. Arthritis Rheum. 2008;59 (3):399-407. doi:10.1002/art.23316

28. Kim C, Linsenmeyer KD, Vlad SC, et al. Prevalence of radiographic and symptomatic hip osteoarthritis in an urban United States community: the Framingham osteoarthritis study. Arthritis Rheumatol. 2014;66(11):3013-3017. doi:10.1002/art.38795 
29. Calce SE, Kurki HK, Weston DA, Gould L. The relationship of age, activity, and body size on osteoarthritis in weight-bearing skeletal regions. Int $J$ Paleopathol. 2018;22:45-53. doi:10.1016/j. ijpp.2018.04.001

30. Fowler-Brown A, Kim DH, Shi L, et al. The mediating effect of leptin on the relationship between body weight and knee osteoarthritis in older adults. Arthritis Rheum. 2015;67:169-175. doi:10.1002/ art.38913

31. Zheng H, Chen C. Body mass index and risk of knee osteoarthritis: systematic review and meta-analysis of prospective studies. BMJ Open. 2015;5:e007568. doi:10.1136/bmjopen-2014-007568

32. Kwon S, Kim W, Yang S, Choi KH. Influence of the type of occupation on osteoarthritis of the knee in men: the Korean National Health and Nutrition Examination Survey 2010-2012. J Occup Health. 2019;61(1):54-62. doi:10.1002/1348-9585.12022

33. Dillon CF, Rasch EK, Gu Q, et al. Prevalence of knee osteoarthritis in the United States: arthritis data from the Third National Health and Nutrition Examination Survey. J Rheumatol. 2006;33(11):2271-2279.

34. Stansfeld SA, Fuhrer R, Shipley MJ, Marmot MG. Work characteristics predict psychiatric disorder: prospective results from the Whitehall II Study. Occup Environ Med. 1999;56(5):302-307. doi:10.1136/oem.56.5.302
35. Wang J. Work stress as a risk factor for major depressive episode(s) Psychol Med. 2005;35(6):865-871. doi:10.1017/S0033291704003241

36. Wang J, Schmitz N, Dewa C, Stansfeld S. Changes in perceived job strain and the risk of major depression: results from a population-based longitudinal study. Am J Epidemiol. 2009;169 (9):1085-1091. doi:10.1093/aje/kwp037

37. Bengtsson C, Theorell T, Klareskog L, Alfredsson L. Psychosocial stress at work and the risk of developing rheumatoid arthritis: results from the Swedish EIRA study. Psychother Psychosom. 2009;78:193-194. doi:10.1159/000209351

38. Cutolo M, Straub RH. Stress as a risk factor in the pathogenesis of rheumatoid arthritis. Neuroimmunomodulat. 2006;13:277-282. doi:10.1159/000104855

39. Harbuz MS, Chover A, Jessop DS. Hypothalamo-pituitary-adrenal axis and chronic immune activation. Ann NY Acad Sci. 2003;992 (1):99-106. doi:10.1111/j.1749-6632.2003.tb03141.x

40. Sternberg EM, Hill JM, Chrousos GP, et al. Inflammatory mediator-induced hypothalamic-pituitary-adrenal axis activation is defective in streptococcal cell wall arthritis-susceptible Lewis rats. Proc Natl Acad Sci. 1989;86:2374-2378. doi:10.1073/ pnas.86.7.2374
Psychology Research and Behavior Management

\section{Publish your work in this journal}

Psychology Research and Behavior Management is an international, peer-reviewed, open access journal focusing on the science of psychology and its application in behavior management to develop improved outcomes in the clinical, educational, sports and business arenas. Specific topics covered in the journal include: Neuroscience, memory and decision making; Behavior modification and management; Clinical

\section{Dovepress}

applications; Business and sports performance management; Social and developmental studies; Animal studies. The manuscript management system is completely online and includes a very quick and fair peer-review system, which is all easy to use. Visit http://www. dovepress.com/testimonials.php to read real quotes from published authors. 